\title{
Transmission dynamics of lumpy skin disease in Ethiopia
}

\author{
W. MOLLA ${ }^{1,2 *}$, K. FRANKENA ${ }^{1}$ AND M. C. M. DE JONG ${ }^{1}$ \\ ${ }^{1}$ Quantitative Veterinary Epidemiology, Wageningen University \& Research, Droevendaalsesteeg 1, 6708 PB \\ Wageningen, The Netherlands \\ ${ }^{2}$ Faculty of Veterinary Medicine, University of Gondar, P.O. Box 196, Gondar, Ethiopia
}

Received 24 April 2017; Final revision 28 June 2017; Accepted 9 July 2017;

first published online 3 August 2017

\section{SUMMARY}

Lumpy skin disease (LSD) is a severe disease of cattle caused by a Capripoxvirus and often caused epidemics in Ethiopia and many other countries. This study was undertaken to quantify the transmission between animals and to estimate the infection reproduction ratio in a predominantly mixed crop-livestock system and in intensive commercial herd types. The transmission parameters were based on a susceptible-infectious-recovered (SIR) epidemic model with environmental transmission and estimated using generalized linear models. The transmission parameters were estimated using a survival rate of infectious virus in the environment equal to 0.325 per day, a value based on the best-fitting statistical model. The transmission rate parameter between animals was $0.072(95 \%$ CI $0.068-0.076)$ per day in the crop-livestock production system, whereas this transmission rate in intensive production system was $0.076(95 \%$ CI $0 \cdot 068-0 \cdot 085)$ per day. The reproduction ratio $(R)$ of LSD between animals in the crop-livestock production system was $1 \cdot 07$, whereas it was 1.09 between animals in the intensive production system. The calculated $R$ provides a baseline against which various control options can be assessed for efficacy.

Key words: Cattle, Ethiopia, LSD, reproduction ratio, transmission.

\section{INTRODUCTION}

Lumpy skin disease (LSD) is a severe viral disease of cattle, which often occurs as regional epidemics within a larger area in which it is endemic. It is caused by lumpy skin disease virus (LSDV), which is of the genus Capripoxvirus of family Poxviridae. LSDV is one of the most important animal poxviruses because of the serious economic consequences in cattle [1,2]. The disease is characterized by lachrymation, fever, nodular lesions on the skin and mucosal surfaces,

\footnotetext{
* Author for correspondence: W. Molla, Quantitative Veterinary Epidemiology, Wageningen University \& Research, Droevendaalsesteeg 1, Radix, building No. 107, 6708 Wageningen, The Netherlands. (E-mail: wassie.abebe@wur.nl,mollawassie@yahoo.com)
}

lymph node enlargement, inflammatory and oedematous swelling of the legs and lameness [1,3].

The disease was reported for the first time in Zambia in 1929 and was confined to Africa until an outbreak occurred in Israel in 1989 [1]. However, currently, the disease is found in most African and Middle East countries, and recently it has spread to eastern and south-eastern European countries. LSDV is clearly on the move in expanding its territory and increasingly becoming a risk for other Asian and European countries [4].

Though the mechanism of LSDV transmission has not yet been clearly established, it is hypothesized that the main mode of transmission of LSDV is via bloodfeeding arthropods [5]. Experimentally, female Aedes aegypti mosquitoes have been shown to transmit LSDV mechanically from infected to susceptible cattle 
[6]. The potential role of ixodid ticks in transmission of LSDV has also been demonstrated in transmission studies including mechanical transmission between cattle for Amblyomma hebraeum and Rhipicephalus appendiculatus, trans-stadial transmission for A. hebraeum and transovarial transmission for Rhipicephalus (Boophilus) decoloratus [7-11]. Transmission of LSDV between infected and susceptible animals by direct contact is considered to be inefficient $[5,12]$.

Data from infectious disease outbreaks are usually incomplete and highly dependent. Incomplete because the infection process is only partially observable, i.e. not all cases may be included due to under-reporting or because of asymptomatic cases, the number of susceptible animals may not be known exactly, individuals who enter or leave the study population may not be recorded accurately, there may be misdiagnosis of cases and flaws in data collection. Data such as daily or weekly case numbers are obviously dependent $[13,14]$. However, transmission under field conditions can be estimated from the number of infections that occurred during the study period or at certain intervals by mathematical modelling using exactly that dependence $[15,16]$.

One parameter often used to characterize transmission is the basic reproduction ratio $\left(R_{0}\right)$ with the effective reproduction ratio $\left(R_{\mathrm{e}}\right)$ being the parameter for the transmission after intervention. $R_{0}$ is defined as the average number of secondary infections caused by one typical infectious individual in a fully susceptible population during its entire infectious period [17], whereas $R_{\mathrm{e}}$ reflects the transmission parameter in a partially susceptible (previously exposed or vaccinated) population [18]. The reproduction ratio $(R)$ is frequently used to describe the behaviour of transmission just after introduction of a disease. Whether an outbreak spreads or dies out depends on whether the reproduction ratio is greater than, or less than, 1 respectively. If $R$ exceeds 1 , a typical (i.e. average) infected animal infects on average more than one susceptible animal, and thus it may cause a major outbreak, while if $R$ is smaller than 1 , the disease will die out or it will at most produce a minor outbreak $[16,19]$.

Despite a large number of LSD outbreaks in many African and Middle East countries, its dynamics are not well studied. Only one study, undertaken by Magori-Cohen et al. [12] in a dairy herd of Israel, reports an estimate for the reproduction ratio of $\operatorname{LSDV}\left(R_{0}=15 \cdot 7\right)$. Therefore, the current study was undertaken with the objectives to better understand the LSDV outbreak dynamics and to quantify the transmission rate parameter and the reproduction ratio between animals.

\section{MATERIALS AND METHODS}

\section{Study area, farms and animals contact patterns}

The study was carried out from 28 April 2014 to 1 February 2015 in the central and north-western parts of Ethiopia. In the north-western part, it involves the cattle population in Mota town and parts of the surrounding five Kebeles (Kebele is the smallest administrative unit in Ethiopia covering an approximate area of $53 \mathrm{~km}^{2}$ ) in Hulet Ejju Enessie district, and Debremarkos University dairy farm in Gozamn district. In the central part, the following herds were enrolled: Selale Dairy Development Private Limited Company (Selale Dairy Dev't PLC) in Wuchale district, Aser Dev't PLC in Sululta district, Ambo University dairy farm in Ambo district, Holeta agricultural research centre farm (Holeta A.R.C) and Holeta special cattle breeding centre (Holeta S.C.B.C) in Welmera district, Selam children village dairy farm in Addis Ababa and Jenesis dairy farm in Ada'a district (Fig. 1). Mota area (Mota town and parts of the surrounding five Kebeles) covers an area of about $5 \mathrm{~km}$ radius. The production system in the Mota area is mainly mixed crop-livestock, while the other herds were commercial dairy herds. Most of the animals in the mixed crop-livestock type of herds were of local Zebu breed, while the intensive herds consisted of Holstein-Zebu cross. Farms were categorized into small ( $<10$ cattle), medium (10-50 cattle), large (51300 cattle), very large (301-700 cattle) and extra-large (>700 cattle) based on the number of cattle they comprised.

The cattle contact network depends on a number of factors, including housing system, size and nature of grazing lands, water points, cattle density and frequency and duration of contacts. This study was undertaken at the family herd (group of animals owned by a family for subsistence) and commercial farm (group of animals owned by a private or public organization for commercial purpose) levels. All smallholder herds enrolled in the study were in the Mota area, but the intensive commercial farms were located in different areas. Since the smallholder herds in the subsistence crop-livestock system (Mota area) are managed extensively, they regularly mixed at shared pastures and watering points, so that they had to be considered as 


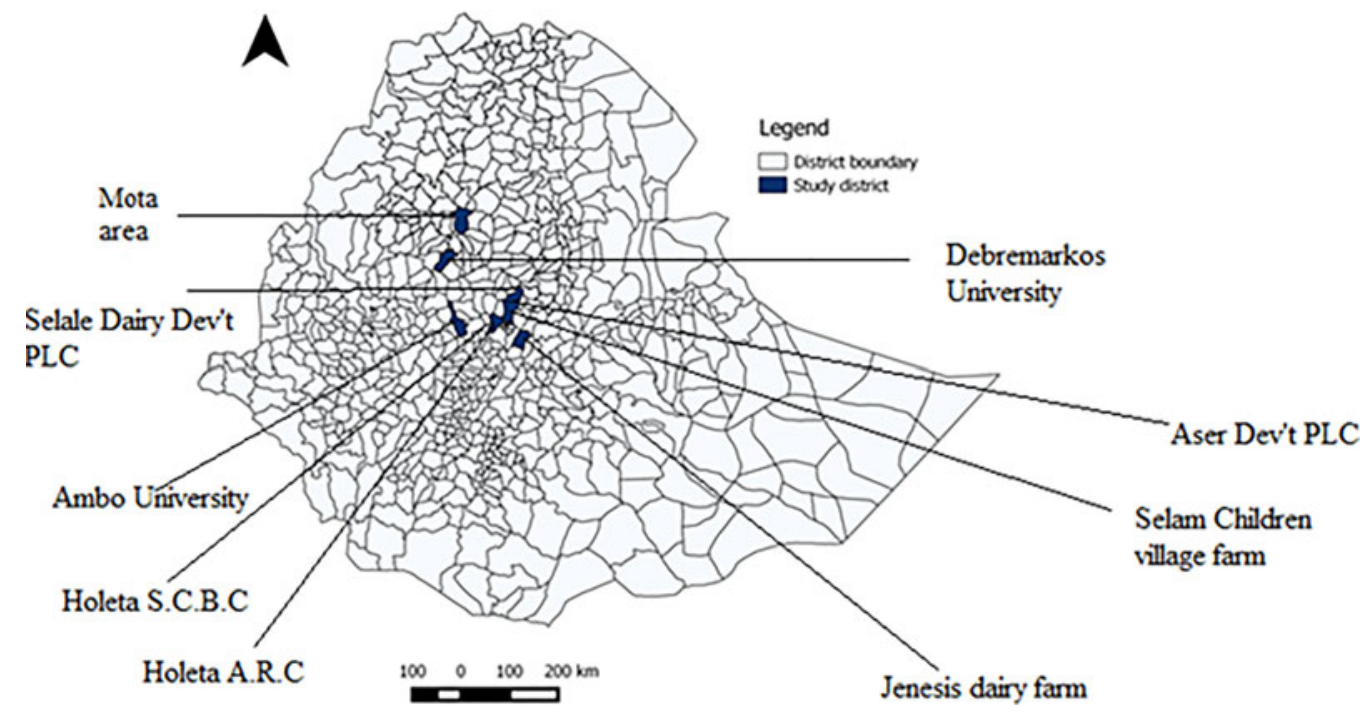

Fig. 1. Map of Ethiopia showing LSD transmission study districts.

one epidemiological unit. Animals in the intensive commercial farms, however, did not have direct contact with animals in other farms in their surroundings and most of them were located in districts far apart from each other.

\section{Period of the epidemic}

To assess the association between LSD epidemics and the season of the outbreak (which has a strong relation with arthropod dynamics), the outbreak duration was categorized into three periods, Belg (period 1), Kiremt (period 2) and Bega (period 3) following the meteorological seasons of Ethiopia. Belg is a short rainy period from February to May over much of the Belg-growing areas. However, over the north-western parts of the country (where Mota area is located), this season is predominantly dry except for the month of May. Kiremt is the period from June to September; and it is the main rainy season in which the major food crops of the country are produced. The magnitude of rainfall during Kiremt is higher as compared with the other seasons for many parts of the country. Bega is the period from October to January. It is normally a dry season characterized by cool nights and hot days over various parts of the country [20].

\section{Infection status of animals}

Herds were visited every week to check whether or not animals showing symptoms of LSD were present. If so, the infection chain within the herd was monitored by visiting the affected herd twice a week throughout the study period and the LSD status (susceptible, infected or recovered) of all animals was determined. At the start of the study, all cattle were assumed to be susceptible. The start of the infectious period was considered to be the day following that on which an animal was first reported with clinical signs of LSD. Infected animals were assumed to stay infectious on average for 10 days taking the duration of viraemia as a proxy for period of infectivity [5,21,22]. An infected animal becomes most infective during the viraemic phase of the disease because the amount of virus in various body tissues and secretions and excretions of the animal become the highest in this phase [22]. Animals that died before the infectious period was completed were considered infectious for the days they lived after being considered infectious.

The contribution of environment $(E)$ to the transmission of LSDV was established by determining a per day survival rate of LSD virus shed into the environment by infected animals. This was done by fitting a GLM model to the collected data by varying the survival rate from $0 \cdot 1$ to $0 \cdot 9$ and selecting the best-fitting model with the lowest AIC value.

Nodular samples were collected from few affected cattle in each herd to confirm the outbreak by using conventional and snapback real-time PCR (polymerase chain reaction) techniques following the procedure described by Gelaye et al. [23].

\section{Estimation of the transmission parameters}

The transmission parameters were estimated based on a susceptible-infectious-recovered (SIR) epidemic 
model in which individuals are either susceptible $(S)$, infected and infectious $(I)$ or recovered and immune or dead $(R)$. During the study, the numbers of $I$ and $S$ observed in each herd were recorded at the start of each observation interval. Animals were registered as a new case $(C)$ on the date they were reported with LSD and as infectious $(I)$ on the next day. Transmission of LSDV between animals has been estimated from the relationship between the number of infectious animals at the start of the time interval and the number of newly infected animals at the end of the time interval. Every new infection is related to the number of animals that were infectious at the time of infection.

The transmission parameters were estimated by a generalized linear model (GLM) [24-27]. The transmission dynamics of LSD between individuals are described by the change in the number of susceptible $(S)$, infectious $(I)$ and recovered $(R)$ animals. Susceptible cattle become infected with a rate of $\beta \times$ $S_{t}\left(I_{t}+E_{t}\right) / N_{t}$. Here $\beta$ is the transmission rate, which can be interpreted as the average number of new infections caused by a typical infectious animal in a fully susceptible population per unit of time, $S_{t}$ is the number of susceptible animals, $I_{t}$ the number of infectious animals, $E_{t}$ contribution of the environment to the transmission and $N_{t}$ is the total number of animals at time $t$, and they are assessed at the start of each observation period. The number of infectious contacts encountered by one individual in a period of length $\Delta t$ follows a Poisson distribution with parameter $\left(\beta\left(I_{t}+E_{t}\right) / N_{t} \times \Delta t\right)$. Hence, the probability of a susceptible animal escaping infection, during a period $\Delta t$ is $\mathrm{e}^{-\beta \times \Delta t\left(I_{t}+E_{t}\right) / N_{t}}$, and thus the probability to become infected is $1-\mathrm{e}^{-\beta \times \Delta t\left(I_{t}+E_{t}\right) / N_{t}}$. This implies that the number of new cases $(C)$ in a period $\Delta t$ follows a binomial distribution. Consequently, the relation between the expected number of cases per unit of time $E(C)$, and $I_{t}, E_{t}, N_{t}, \beta$ and $S_{t}$ can be formulated as $E\left(C_{t}\right)=S_{t}\left(1-\mathrm{e}^{-\beta \times \Delta t\left(I_{t}+E_{t}\right) / N_{t}}\right)$. The transmission parameter $\beta\left(\beta=\mathrm{e}^{b}\right.$, where $b$ is the regression coefficient of the intercept of the model) was estimated using a GLM with a complementary-log-log link function and $\log \left(\Delta t\left(I_{t}+E_{t} / N_{t}\right)\right)$ as offset. Finally, we obtained $R$ by multiplying $\beta$ with the average length of the infectious period $[19,24,27]$ times a factor of $(1-E)^{-1}$, which incorporates the environmental contribution.

The $\chi^{2}$ test was used to test the association of morbidity and mortality with production systems and GLM to compare transmission rates between the three meteorological periods, production systems and herd sizes.

All analyses were carried out in Stata 14.

\section{RESULTS}

\section{Descriptive statistics}

During the study period, a total of 14319 individual animals from 2446 herds were followed for LSD occurrence. A total of 12509 animals (in 2438 herds) were kept in the crop-livestock system and 1810 animals (in eight herds) in the intensive production system (Table 1).

The number of animals and herds affected, morbidity and mortality due to LSD per production system are indicated in Table 1 . The morbidity was significantly higher in the intensive $(17 \cdot 5 \%)$ compared with the crop-livestock $(10 \cdot 1 \%)$ system. The mortality was also significantly higher in the intensive $(4 \cdot 0 \%)$ than in the crop-livestock $(0 \cdot 7 \%)$ system (Table 1$)$.

In the Mota area, the LSD outbreak started at the end of April 2014, but in the other study farms, the outbreak started later and continued until the first week of February 2015. The epidemic curve of the LSD outbreak in the Mota area is presented in Fig. 2.

\section{Transmission of LSD between animals}

The contribution of the environment to the transmission $(E)$ and the number of $C, I$ and $S$ animals in the Mota area are listed for each day of the epidemic (Supplementary Table S1). The transmission rate parameter between animals in the dominantly subsistent crop-livestock production system was 0.072 (95\% CI $0 \cdot 068-0.076$ ) per day (Table 2), whereas in the intensive production system, it was $0.076(0.068-0.085)$ per day (Table 3). The survival rate of infectious LSD virus in the environment was estimated as 0.325 per day based on the best-fitting statistical model, and this value was used to account for the indirect transmission (excluding the immediate or direct transmission) of the virus. The average LSD infectious periods for animals are indicated in Tables 2 and 3 for both production systems.

Based on the survival rate of LSDV in the environment, the multiplication factor of $R$ was $1 \cdot 5$. Then a reproduction ratio of 1.07 between animals was calculated in the crop-livestock production system in the Mota area (Table 2). $R$ values between animals vary from 0.90 (Aser dairy farm) to $1 \cdot 15$ (Ambo university) in the eight intensive farms, while the overall $R$ value for intensive dairy farms was 1.09 (Table 3). Major outbreaks have been observed in the Ambo University, Holeta S.C.B.C, Holeta A.R.C, Selale 
Table 1. LSD morbidity and mortality in subsistence crop-livestock and intensive commercial farms

\begin{tabular}{|c|c|c|c|c|c|c|c|c|}
\hline Area/farm & $\begin{array}{l}\text { Dominant } \\
\text { production } \\
\text { system }\end{array}$ & $\begin{array}{l}\text { No. of } \\
\text { total } \\
\text { herds }\end{array}$ & $\begin{array}{l}\text { No. of } \\
\text { total } \\
\text { animals }\end{array}$ & $\begin{array}{l}\text { No. of } \\
\text { affected } \\
\text { herds }\end{array}$ & $\begin{array}{l}\text { No. of } \\
\text { infected } \\
\text { animals }\end{array}$ & $\begin{array}{l}\text { Morbidity } \\
\text { in } \%\end{array}$ & $\begin{array}{l}\text { No. } \\
\text { died }\end{array}$ & $\begin{array}{l}\text { Mortality } \\
\text { in } \%\end{array}$ \\
\hline Mota area ${ }^{\mathrm{a}}$ & Crop-livestock & 2438 & 12509 & 841 & 1266 & $10 \cdot 12$ & 81 & 0.65 \\
\hline $\begin{array}{l}\text { Ambo } \\
\text { University }\end{array}$ & Intensive & 1 & 86 & 1 & 24 & $27 \cdot 91$ & 6 & $6 \cdot 98$ \\
\hline Aser Dev't PLC & Intensive & 1 & 50 & 1 & 5 & $10 \cdot 00$ & 0 & 0 \\
\hline $\begin{array}{l}\text { Debremarkos } \\
\text { University }\end{array}$ & Intensive & 1 & 42 & 1 & 6 & $14 \cdot 29$ & 0 & 0 \\
\hline Holeta S.C.B.C & Intensive & 1 & 429 & 1 & 88 & $20 \cdot 51$ & 19 & $4 \cdot 43$ \\
\hline Holeta A.R.C & Intensive & 1 & 623 & 1 & 84 & $13 \cdot 48$ & 6 & $0 \cdot 96$ \\
\hline $\begin{array}{l}\text { Jenesis dairy } \\
\text { farm }\end{array}$ & Intensive & 1 & 204 & 1 & 8 & 3.92 & 0 & 0 \\
\hline $\begin{array}{l}\text { Selale Dairy } \\
\text { Dev't PLC }\end{array}$ & Intensive & 1 & 330 & 1 & 93 & $28 \cdot 18$ & 40 & $12 \cdot 12$ \\
\hline $\begin{array}{l}\text { Selam Children } \\
\text { village farm }\end{array}$ & Intensive & 1 & 46 & 1 & 9 & $19 \cdot 57$ & 2 & $4 \cdot 35$ \\
\hline Intensive subtotal & & 8 & 1810 & 8 & 317 & $17 \cdot 51$ & 73 & $4 \cdot 03$ \\
\hline
\end{tabular}

${ }^{\text {a }}$ All herds and animals at risk considered.

$\chi^{2}(1)=87 \cdot 89, P=0.000$ for differences in morbidity between animals in crop-livestock and intensive systems. $\chi^{2}(1)=170 \cdot 35, P=0 \cdot 000$ for differences in mortality between animals in crop-livestock and intensive systems.

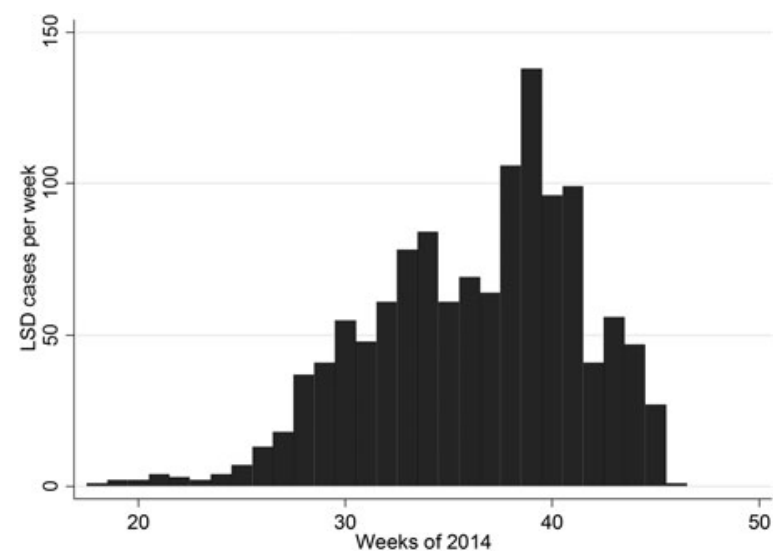

Fig. 2. Epidemic curve of lumpy skin disease in Mota area, Ethiopia, in 2014.

Dairy Dev't PLC, Selam children village dairy herds and Mota area (Table 3, Supplementary Table S2).

Transmission parameter rates $(\beta)$ between animals for subsistence crop-livestock production system in the Mota area showed significant differences between periods 2 and $3(P<0 \cdot 05)$ (Table 2). However, the transmission rates did not significantly differ between production systems and herd sizes.

\section{DISCUSSION}

The $10 \cdot 1 \%$ and $17 \cdot 5 \%$ animal-level morbidity of LSD reported in the current study in the subsistence crop-livestock production system and intensive system, respectively, are within the range of what has been reported in previous works $[1,28]$. Similarly, the mortality was higher in the intensive production system than in the crop-livestock system. These significant differences in morbidity and mortality between animals in the two systems might be explained by the breed of cattle raised in the two systems. In the intensive system, Holstein-Friesian local cross was the dominant breed that is more susceptible and more severely affected by LSD than the local Zebu breed [1,29], which is the breed commonly found in the crop-livestock production system. The other reason might be related to the way we calculated the morbidity and mortality in both systems. In the crop-livestock system, all animals in the Mota area whether or not they were within an infected herd or not, were included in the denominator, whereas in the intensive system, only the number of animals in infected herds were in the denominator to calculate the morbidity and mortality.

The infectious period and survival of the virus in the environment are important parameters in estimating the reproduction ratio, but these parameters were not reported in any of the previous studies. However, information about these parameters is essential for formulating appropriate prevention and control strategies for LSD. In this study too, we did not estimate the infectious period of an infected animal and the 
Table 2. Transmission parameters of LSD virus between animals by meteorological period in dominantly croplivestock system (Mota area), Ethiopia, during the 2014 epidemic

\begin{tabular}{|c|c|c|c|c|c|c|c|}
\hline Transmission & Period & $\begin{array}{l}\text { No. of } \\
\text { weeks }\end{array}$ & $\begin{array}{l}\text { No. of } \\
\text { cases }\end{array}$ & $\beta(95 \% \mathrm{CI})$ per day & $P$-value & $\begin{array}{l}\text { Average inf. } \\
\text { period in days }\end{array}$ & $R^{\mathrm{a}}(95 \% \mathrm{CI})$ \\
\hline \multirow[t]{4}{*}{ Between animals } & $1\left(18-22^{b}\right)$ & 5 & 12 & $0 \cdot 077(0 \cdot 043-0 \cdot 139)$ & $0 \cdot 315$ & $8 \cdot 25$ & $0.95(0.53-1.72)$ \\
\hline & $2(23-39)$ & 17 & 887 & $0.080(0.075-0.085)$ & $0 \cdot 000$ & $9 \cdot 03$ & $1 \cdot 08(1 \cdot 02-1 \cdot 15)$ \\
\hline & $3(40-47)$ & 8 & 367 & $0.057(0.051-0.063)$ & Ref & $12 \cdot 11$ & $1.04(0.93-1 \cdot 14)$ \\
\hline & Overall & 30 & 1266 & $0.072(0.068-0.076)$ & & $9 \cdot 92$ & $1 \cdot 07(1 \cdot 01-1 \cdot 13)$ \\
\hline
\end{tabular}

${ }^{\mathrm{a}} R$ is obtained after multiplying the product of $\beta$ and infectious period by a factor of $1 \cdot 5$, which is a sum of the infectivity of the infected animal (1) and infectivity of the virus accumulated in the environment $(0 \cdot 5)$ at a particular date of the epidemic.

${ }^{\mathrm{b}}$ Week number.

Table 3. Transmission parameters and reproduction ratios of LSD virus within eight intensive dairy herds and Mota area during the 2014/2015 epidemic

\begin{tabular}{|c|c|c|c|c|c|c|c|}
\hline Area/farm & $\begin{array}{l}\text { Production } \\
\text { system }\end{array}$ & $\begin{array}{l}\text { No. of } \\
\text { animals }\end{array}$ & $\begin{array}{l}\text { No. of } \\
\text { cases }\end{array}$ & $\begin{array}{l}\text { Outbreak } \\
\text { dur. in } \\
\text { weeks }\end{array}$ & $\begin{array}{l}\beta(95 \% \mathrm{CI}) \\
\text { per day }\end{array}$ & $\begin{array}{l}\text { Average } \\
\text { Inf. period } \\
\text { in days }\end{array}$ & $R^{\mathrm{a}}(95 \% \mathrm{CI})$ \\
\hline Ambo University & Intensive & 86 & 24 & 8 & $0.086(0 \cdot 057-0 \cdot 130)$ & $8 \cdot 92$ & $1 \cdot 15(0 \cdot 76-1 \cdot 74)$ \\
\hline Aser Dev't PLC & Intensive & 50 & 5 & 4 & $0.060(0.022-0 \cdot 159)$ & 10 & $0 \cdot 90(0 \cdot 33-2 \cdot 39)$ \\
\hline $\begin{array}{l}\text { Debremarkos } \\
\text { University }\end{array}$ & Intensive & 42 & 6 & 4 & $0.064(0 \cdot 027-0 \cdot 154)$ & 10 & $0 \cdot 96(0 \cdot 41-2 \cdot 31)$ \\
\hline Holeta S.C.B.C & Intensive & 429 & 88 & 15 & $0.078(0 \cdot 063-0.096)$ & $9 \cdot 51$ & $1 \cdot 11(0 \cdot 90-1 \cdot 37)$ \\
\hline Holeta A.R.C & Intensive & 623 & 84 & 17 & $0 \cdot 071(0 \cdot 057-0 \cdot 088)$ & $9 \cdot 96$ & $1 \cdot 06(0 \cdot 85-1 \cdot 31)$ \\
\hline $\begin{array}{l}\text { Jenesis dairy } \\
\text { farm }\end{array}$ & Intensive & 204 & 8 & 8 & $0 \cdot 061(0 \cdot 029-0 \cdot 128)$ & 10 & $0.92(0 \cdot 44-1.92)$ \\
\hline $\begin{array}{r}\text { Selale Dairy } \\
\text { Dev't PLC }\end{array}$ & Intensive & 330 & 93 & 21 & $0 \cdot 082(0 \cdot 066-0 \cdot 100)$ & $9 \cdot 24$ & $1 \cdot 14(0 \cdot 91-1 \cdot 39)$ \\
\hline $\begin{array}{l}\text { Selam Children } \\
\text { village farm }\end{array}$ & Intensive & 46 & 9 & 7 & $0.068(0 \cdot 034-0 \cdot 137)$ & 10 & $1 \cdot 02(0 \cdot 51-2 \cdot 06)$ \\
\hline Intensive total & & 1810 & 317 & 84 & $0 \cdot 076(0 \cdot 068-0 \cdot 085)$ & $9 \cdot 55$ & $1.09(0.97-1 \cdot 22)$ \\
\hline Mota area & Crop-livestock & 12509 & 1266 & 30 & $0.072(0.068-0.076)$ & $9 \cdot 92$ & $1 \cdot 07(1 \cdot 01-1 \cdot 13)$ \\
\hline Overall & & 14319 & 1583 & 114 & $0.073(0.069-0.076)$ & $9 \cdot 84$ & $1 \cdot 08(1 \cdot 02-1 \cdot 12)$ \\
\hline
\end{tabular}

${ }^{\mathrm{a}} R$ is obtained after multiplying the product of $\beta$ and infectious period by a factor of $1 \cdot 5$, which is a sum of the infectivity of the infected animal (1) and the infectivity of the virus accumulated in the environment (0.5) at a particular date of the epidemic.

survival rate of the virus in the environment because the study set up did not allow us to do that; instead we parametrized the infectious period from information obtained in the literature and the survival rate by searching for the best-fitting model. We set the infectious period to 10 days for an infected animal by taking into account the duration of virus isolation in blood for 10-12 days [5,21]. Furthermore, there is no clear information when infected animals become infectious, which is important to know for the quantification of transmission. Infectiousness may start before or after the onset of clinical disease, but for this study, we set the start of the infectious period as
$24 \mathrm{~h}$ after the onset of the disease considering that LSDV isolation from blood and skin samples were achieved in most of the cases after the affected animals showed fever [21]. Regarding the survival rate of the virus in the environment, literature indicates that the virus survives in air-dried hides for at least 18 days, in necrotic skin nodules for up to 33 days or longer, and for up to 35 days in desiccated crust [30], but it is not clear whether the viruses surviving in these foci contribute to the transmission of LSD. Taking this information into consideration, we fitted a model (by selecting the best-fitting model) to our data and found a survival rate of 0.325 per day, 
which was used in the offset to incorporate the contribution of environment to the transmission of LSDV. The implication of this survival rate is that the infectivity is increased by almost $50 \%$.

To our knowledge, this is the first field study in Ethiopia in which transmission rate parameters have been quantified. This knowledge is helpful to design sets of measures that efficiently eliminate the virus. In the study, LSDV transmission was modelled by considering it as direct transmission. It is widely believed that LSDV is transmitted from infected to susceptible hosts indirectly through mechanical arthropod vectors, though the importance of the different types of arthropod vectors in the transmission of LSD virus in field conditions is not fully understood [5,12]. If a blood-feeding arthropod feeds briefly on viraemic cattle and is interrupted, a subsequent immediate feeding on a second animal could result in virus transmission. The virus does not replicate within the vector [31], which thus serves as a passive carrier to transmit the disease. The vector in this case serves only as a bridge for the transmission of LSDV from infected to susceptible cattle, so that we did not incorporate the vectors in the transmission model.

During the outbreak, LSDV was transmitted between animals with a rate of 0.072 per day in the crop-livestock production system. The transmission chain from which specific infected cattle to which susceptible cattle was not clearly identified due to the free movement and mixing up of animals in the area and mechanical transmission of the disease by arthropods vectors. Hence, the transmission rate between animals was calculated by considering the cattle population in the area as one population.

In the Mota area, the transmission rate of LSD was also estimated for different time periods and the results indicate a significant difference in daily transmission rates between periods. The per day transmission rate between animals was higher at the beginning of the outbreak (in periods 1 and 2 compared with period 3). This was expected, because during these periods the susceptible population was not yet depleted and no specific measures were taken to reduce transmission. This result indicates that starting implementation of control measures at early stage of the outbreak is necessary to halt the spread of the disease. We did not assess the periodic variation of transmission rate in farms of intensive production system due to the fact that the outbreaks in those farms were relatively short and it was not convenient to divide the time into different periods, as in most occasions, the outbreak fell in one period.
In this study, we estimated an $R$ value of 1.07 between animals in the crop-livestock area. The $R$ values within the intensive farms were also in the range of $0 \cdot 90-1 \cdot 15$ with an overall value of $1 \cdot 09$. These $R$ values are low compared with the $R$ value of 15.7 reported for indirect transmission within a commercial dairy farm in Israel [12]. The difference might be explained by the method how $R$ is calculated, different study population, the environmental difference and the production set up.

Knowledge of within-herd transmission is necessary to assess the effectiveness of intervention measures and to design effective monitoring programmes [3234]. In this study, we estimated that $R$ was $>1$ between animals in the dominantly crop-livestock system and in some farms of the intensive production system. This sheds light on LSDV transmission and further work should focus on the effect of control measures that add to bring $R$ below the threshold level. LSD control will be achieved if both reproduction ratios, among animals and between herds are $<1$; and also if $R$ among animals is $>1$, but $R$, between herds is below 1. Infections with low $R$ values are less difficult to control than those with a high $R$ value [34]. Our estimates of $R$ provide a baseline against which various control options can be assessed for efficacy. In general, from this study, it can be concluded that transmission of LSDV between animals in Ethiopia is low.

\section{SUPPLEMENTARY MATERIAL}

The supplementary material for this article can be found at https://doi.org/10.1017/S0950268817001637.

\section{ACKNOWLEDGEMENTS}

The authors would like to thank animal health personnel and the herd owners for their kind collaboration in collecting and providing information for the study.

This work was supported by Nuffic (the Netherlands organization for international cooperation in higher education).

\section{DECLARATION OF INTEREST}

None.

\section{REFERENCES}

1. Davies FG. Lumpy skin disease, an African capripox virus disease of cattle. British Veterinary Journal 1991; 147: 489-503. 
2. Carn VM. Control of Capripoxvirus infections. Vaccine 1993; 11: 1275-1279.

3. Tuppurainen ES, Oura CA. Review: lumpy skin disease: an emerging threat to Europe, the Middle East and Asia. Transboundary and Emerging Diseases 2012; 59: 40-48.

4. Tuppurainen ES, et al. Review: Capripoxvirus diseases: current status and opportunities for control. Transboundary and Emerging Diseases 2017; 64: 729-745. doi: 101111/ tbed12444.

5. Carn VM, Kitching RP. An investigation of possible routes of transmission of lumpy skin disease virus (Neethling). Epidemiology and Infection 1995; 114: 219-226.

6. Chihota CM, et al. Mechanical transmission of lumpy skin disease virus by Aedes aegypti (Diptera: Culicidae). Epidemiology and Infection 2001; 126: 317-321.

7. Tuppurainen ES, et al. A potential role for ixodid (hard) tick vectors in the transmission of lumpy skin disease virus in cattle. Transboundary and Emerging Diseases 2011; 58: 93-104.

8. Tuppurainen ES, et al. Mechanical transmission of lumpy skin disease virus by Rhipicephalus appendiculatus male ticks. Epidemiology and Infection 2013; 141: 425-430.

9. Tuppurainen ES, et al. Evidence of vertical transmission of lumpy skin disease virus in Rhipicephalus decoloratus ticks. Ticks and Tick-borne Diseases 2013; 4: 329-333.

10. Lubinga JC, et al. Detection of lumpy skin disease virus in saliva of ticks fed on lumpy skin disease virus-infected cattle. Experimental \& Applied Acarology 2013; 61: 129-138.

11. Lubinga JC, et al. Evidence of lumpy skin disease virus over-wintering by transstadial persistence in Amblyomma hebraeum and transovarial persistence in Rhipicephalus decoloratus ticks. Experimental \& Applied Acarology 2014; 62: 77-90.

12. Magori-Cohen R, et al. Mathematical modelling and evaluation of the different routes of transmission of lumpy skin disease virus. Veterinary Research 2012; 43: 1. doi: 10.1186/1297-9716-43-1.

13. Becker NG, Britton T. Statistical studies of infectious disease incidence. Journal of the Royal Statistical Society: series B 1999; 61: 287-307.

14. O'Neill PD. Introduction and snapshot review: relating infectious disease transmission models to data. Statistics in Medicine 2010; 29: 2069-2077.

15. Kroese AH, De Jong MCM. Design and analysis of transmission experiments. In: Menzies FD, Reid SWJ, eds. Proceedings of the Society for Veterinary Epidemiology and Preventive Medicine. Society for Veterinary Epidemiology and Preventive Medicine, Noordwijkerhout, The Netherlands, 2001, pp. xxi-xxxvii.

16. Velthuis AGJ, et al. Quantification of transmission in one-to-one experiments. Epidemiology and Infection 2002; 128: 193-204.

17. Diekmann O, Heesterbeek JAP, Metz JAJ. On the definition and the computation of the basic reproduction ratio $\mathrm{R} 0$ in models for infectious diseases in heterogeneous populations. Journal of Mathematical Biology 1990; 28: 365-382.

18. Chowell G, Nishiura H. Transmission dynamics and control of Ebola virus disease (EVD): a review.
BMC Medicine 2014; 12: 196. doi: 10.1186/ s12916-014-0196-0.

19. van Roermund HJW, et al. No between-pen transmission of foot-and-mouth disease virus in vaccinated pigs. Vaccine 2010; 28: 4452-4461.

20. NMA. Annual climate bulletin. National meteorological agency (NMA), Addis Ababa Ethiopia (http://www. ethiomet.gov.et/bulletins/view_pdf/348/2013_annual_ bulletin.pdf). Accessed 30 June, 2016. 2013.

21. Tuppurainen ESM, Venter EH, Coetzer JAW. The detection of lumpy skin disease virus in samples of experimentally infected cattle using different diagnostic techniques. Onderstepoort Journal of Veterinary Research 2005; 72: 153-164.

22. Woods JA. Lumpy skin disease virus. In: Dinter Z, Morein $\mathrm{B}$, eds. Virus Infections of Ruminants. Amsterdam: Elsevier Science publishers B. V., 1990, pp. 53-67.

23. Gelaye E, et al. Development of a cost-effective method for Capripoxvirus genotyping using snapback primer and dsDNA intercalating dye. PLOS ONE 2013; 8: e75971.

24. Velthuis AGJ, et al. Design and analysis of an Actinobacillus pleuropneumoniae transmission experiment. Preventive Veterinary Medicine 2003; 60: 53-68.

25. Heffernan JM, Smith RJ, Wahl LM. Perspectives on the basic reproductive ratio. Journal of the Royal Society Interface 2005; 2: 281-293.

26. Chowell G, Nishiura H, Bettencourt LM. Comparative estimation of the reproduction number for pandemic influenza from daily case notification data. Journal of the Royal Society Interface 2007; 4: 155-166.

27. Bravo de Rueda C, et al. Quantification of transmission of foot-and-mouth disease virus caused by an environment contaminated with secretions and excretions from infected calves. Veterinary Research 2015; 46: 43. doi: 10.1186/s13567-015-0156-5.

28. Woods JA. Lumpy skin disease - a review. Tropical Animal Health and Production 1988; 20: 11-17.

29. Manual of diagnostic tests and vaccines for terrestrial animals, chapter $2 \cdot 4 \cdot 14$, Lumpy skin disease. OIE, Paris (http://web.oie.int/eng/normes/MMANUAL/A Index.htm) (accessed 26 February 2016).

30. Lumpy skin disease (http://www.oie.int/fileadmin/Home/ eng/Animal_Health_in_the_World/docs/pdf/Disease_ cards/LUMPY_SKIN_DISEASE_FINAL.pdf). Accessed 10 October 2016.

31. Goddard J. Infectious Diseases and Arthropods, 2nd edn. USA: Humana Press, 2008, pp. 19-28.

32. Stegeman A, et al. Transmission of classical swine fever virus within herds during the 1997-1998 epidemic in the Netherlands. Preventive Veterinary Medicine 1999; 42: 201-218.

33. Graat EAM, et al. Modelling the effect of surveillance programmes on spread of bovine herpesvirus 1 between certified cattle herds. Veterinary Microbiology 2001; 79: 193-208.

34. Hage JJ, et al. Transmission of bovine herpesvirus 1 within and between herds on an island with a BHV1 control programme. Epidemiology and Infection 2003; 130: $541-552$. 